\title{
Furió, A. (Ed.) (2020). En torno a la economía mediterránea medieval. Estudios dedicados a Paulino Iradiel. València: Publicacions de la Universitat de València. 402 pp. ISBN: 978-84-9134-661-6
}

Author:

Esther Tello Hernández

Departament Història Medieval i Ciències i Tècniques Historiogràfiques. Àrea d'Història Medieval.

Universitat de València (Valencia, Spain)

esther.tello@uv.es

https://orcid.org/0000-0002-5985-3791

Date of reception: 22/05/21

Date of acceptance: 23/05/21

Citation:

Tello Hernández, E. (2021). Book review: Furió, A. (Ed.) (2020). En torno a la economía mediterránea medieval. Estudios dedicados a Paulino Iradiel. Anales de la Universidad de Alicante. Historia Medieval, (22), 413-415.

https://doi.org/10.14198/medieval.20013

C 2021 Esther Tello Hernández

Licence: This work is licensed under a Creative Commons Attribution 4.0 International License (CC BY 4.0).

c) (i)

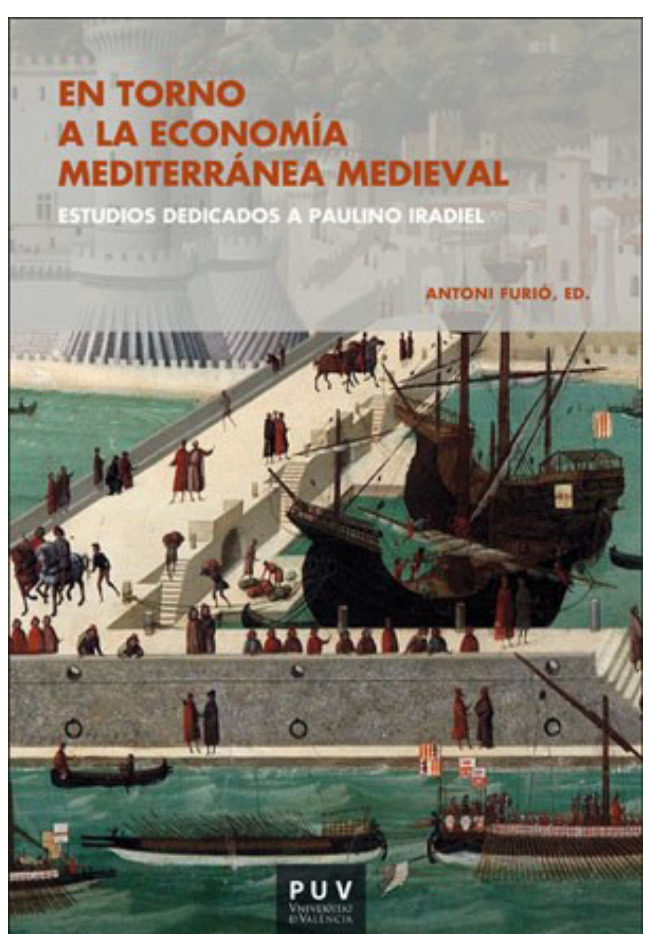

El libro que aquí se reseña es un reconocimiento a la trayectoria científica del catedrático de Historia Medieval de la Universitat de València Paulino Iradiel. En particular, el estudio reúne 15 artículos de reconocidos investigadores y colegas que han estado vinculados a la trayectoria el dr. Iradiel desde sus inicios en Salamanca hasta Valencia, pasando, como no, por Italia y Francia. Todos ellos abordan la historia del mediterráneo occidental durante los siglos bajomedievales desde diferentes puntos de vista, argumento - tal como indica Antoni Furió en el prólogo- en el que se han centrado buena parte de la producción científica del homenajeado.

Tras la extensa presentación realizada por Antoni Furió y que contextualiza el marco historiográfico del libro y la trayectoria de los autores implicados, el artículo de Alberto Grohman aporta una reflexión en torno a cómo se ha tratado en la his- 
toriografía las fuentes documentales económicas. Para ello, repasa lo que escribieron sobre esta cuestión historiadores y filósofos como M. Foucault, F. Braudel o M. Bloch, entre otros, y presta atención al devenir de la historia cuantitativa o la historia del trabajo. Precisamente, la temática del trabajo y los trabajadores es en la que se centra Giampiero Nigro en su artículo. Nigro toma como observatorio la industria textil florentina de los siglos XIV y XVI. En concreto, aborda la interesante cuestión del ritmo y los tiempos de producción y la importancia capital de la banca, el transporte y la innovación, incluyendo aquí la moda, entre otros aspectos. En tercer lugar, centrándose en la producción lanera, Giuliano Pinto realiza un amplio recorrido sobre la importancia económica y el peso social que tuvo la manufactura de la lana en la Italia bajomedieval. El autor pone ejemplos de varias ciudades italianas que legislaron en torno a esta cuestión, mostrando claramente cómo era un asunto primordial en el ordenamiento urbano. Por su parte, Élisabeth Crouzet-Pavan aborda en su artículo los oficios en Venecia a finales de la Edad Media. Para ello, también se centra en la legislación urbana y, sobre todo, en la regulación de los modos de producción en los siglos XV y XVI. Sobre la retribución del trabajo escribe asimismo Franco Franceschi. A través de la Italia centro septentrional, analiza la interesante cuestión del binomio trabajador y pobreza y el papel esencial que jugaron en todo ello las cofradías y demás corporaciones asistenciales.

Dejando de lado el mundo del trabajo, Gabriella Piccini se centra en los prestamistas de la Siena del trescientos. A través de una documentación sistemática de la década de 1330, Piccini hace un recorrido por los diferentes tipos de perfiles de prestamistas que actuaban en la ciudad de Siena y su vinculación con los cargos urbanos. Pasando a la península ibérica, pero continuando con el tema financiero, Juan Carrasco escribe un amplio artículo sobre el crédito en la Navarra de finales del siglo XIV. En particular, el autor profundiza en la morosidad, las condenas por los impagos de deudas y el fraude por usura y falseados documentales en torno a la cuestión del crédito cristiano.

Otro conjunto de artículos tiene como temática el cultivo. Alfio Cortonesi toma como observatorio el camino histórico de la vía Romea-Francígena y profundiza en la distribución del paisaje: desde los pastos y tierras de cultivo, hasta elementos que articulan el territorio como hospitales o monasterios. Por su parte, Antoni Riera i Melis analiza el cultivo y consumo del arroz en los marjales valencianos y en Cataluña. En una primera parte expone cómo se fue introduciendo este cultivo desde el valle de Yangtsé y la expansión de este en época islámica. En la segunda parte del artículo expone, sobre todo, la difusión por tierras catalanas y su exportación a otras zonas peninsulares y del mediterráneo.

Centrado también en la actividad económica, Amedeo Feniello toma como observatorio el mercado y el consumo en el Nápoles del siglo XIV. En este caso, se centra en el desarrollo de la actividad económica y en los diferentes roles de las compañías 
mercantiles que contribuyeron a integrar el mercado napolitano en los circuitos italianos e internacionales. Por su parte, José Ángel Sesma trata el tema del comercio entre Castilla y Aragón a mediados del siglo XV. Gracias a la documentación generada por las aduanas es posible conocer con detalle los intercambios comerciales que se llevaban a cabo entre estos territorios y su potencial económico. Sin embargo, la guerra entre las coronas de Castilla y Aragón de mitad del siglo XV hizo que las entradas y salidas de productos por estas tierras de frontera cayera de manera fulminante, tardando mucho tiempo en recuperarse. Volviendo al mar mediterráneo, Luciano Palermo se centra en los puertos del mar Tirreno y, en especial, toma como objeto de estudio el sistema portuario pontificio durante los siglos bajomedievales y modernos. En su artículo hace un recorrido por la expansión comercial de centros como Civitavecchia y Ostia. Siguiendo en el mediterráneo, José Enrique López de Coca expone la figura de Alonso Sánchez y el monopolio de la Contratación de Orán a comienzos del siglo XVI. Tras una descripción de este agente, trata las relaciones comerciales entre Orán y Castilla y el breve monopolio ejercido por Alonso Sánchez. En la segunda parte del artículo, el autor da a conocer unas ricas cuentas de la contratación de Orán y el nombre de los factores y agentes en activo durante este periodo.

Finalmente, en otro conjunto de artículos, el recientemente fallecido Alfonso Franco Silva analiza la hacienda de María de Saavedra a través de un inventario y que, además, permite conocer mejor las posesiones de conjunto de este linaje sevillano. En particular, transcribe y da a conocer las tierras que poseía María de Saavedra, el ganado y los bienes muebles e inmuebles. Por su parte, José María Monsalvo Antón aborda el tema de la conflictividad al sur del Duero a través de algunos linajes de caballería urbana. Para ello, analiza los diferentes tipos de asociacionismo y agrupamientos en los núcleos del sur del Duero y su evolución a lo largo de los siglos bajomedievales. Finalmente, José Ángel García de Cortázar estudia el tema del patronato de las iglesias del señorío de Vizcaya a finales de la Edad Media. En concreto, este territorio, que pertenecía eclesiásticamente a las diócesis de Calahorra y Burgos, sufrió un fuerte absentismo del obispo desde los siglos plenomedievales. Tomando como punto de partida este hecho y por el propio devenir histórico, el autor se centra en el papel de los patronos laicos y los hidalgos que estuvieron fuertemente vinculados a estos núcleos eclesiásticos. 